\title{
TÉCNICAS DE REDUÇÃO DE DANOS CAUSADOS POR ROEDORES EM POVOAMENTOS DE PINUS
}

\author{
Juares Andreiv*; Carlos Firkowski** \\ *Eng. Florestal, M.Sc. \\ **Eng. Florestal, Ph.D., Depto. de Ciências Florestais, UFPR - firko@ufpr.br \\ Recebido para publicação: 12/06/2002 - Aceito para publicação: 13/06/2006
}

\begin{abstract}
Resumo
Os roedores são citados como causadores de danos em ambientes naturais em várias partes do mundo. No Brasil, apesar de ser um fato já comprovado, nenhum estudo efetivo foi realizado. Este trabalho apresenta os resultados de testes com diferentes técnicas para a redução de danos causados por pequenos roedores. Os danos são provocados na base de árvores de pinus, através de roedura e retirada da casca, ocasionando lesão parcial ou total na circunferência do tronco. Os experimentos indicaram roçada e utilização de gado como técnicas que modificam significativamente o ambiente, através da eliminação total do sub-bosque, resultando na maior eficiência de redução de danos causados por roedores em povoamentos de pinus.

Palavras-chave: Danos em pinus; roedores; controle.
\end{abstract}

\begin{abstract}
Techiniques for damage reduction caused by rodents in pine commerciail forests. Rodents are known to cause damages in natural environments in many parts of the world. Although there are a lot of reports of damage in Brazilian pine commercial forests, effective research on the subject has not been done. This study presents the results of field tests and observation with different techniques used for the reduction of damage caused by small rodents that nibble and remove the bark, thus producing partial or total wounds in the circumference of the trunk. The clearing of undergrowth and the use of cattle for grazing appeared to be the techniques that highly modify the environment through the total elimination of the cover weeds and are therefore the most efficient ones in the reduction of damages in commercial forests.

Keywords: Damage in pine; rodents; control.
\end{abstract}

\section{INTRODUÇÃO}

Os roedores são organismos constituintes e essenciais nos processos ecológicos em diferentes ambientes naturais, como na dispersão de sementes. Nesses ambientes, os roedores também causam danos ao se alimentarem e ao desgastarem seus dentes incisivos, que crescem continuamente e durante a vida toda, roendo frutos, sementes, troncos e raízes Devido ao equilíbrio natural existente, a densidade de roedores é mantida num certo nível por pressões do ambiente, tomando esses danos componentes no funcionamento do ecossistema. Em florestas comerciais, ou seja, constituídas por uma única espécie, onde o equilíbrio natural foi profundamente alterado, a densidade de uma espécie animal pode aumentar consideravelmente pela falta de inimigos naturais e por sua capacidade de ocupação. Schönherr (1991) cita que plantios florestais homogêneos representam um sistema vulnerável que tende a facilitar a multiplicação em massa de uma espécie animal.

No mundo, existem vários relatos sobre danos causados por animais silvestres na vegetação. National Academy of Sciences $(1975 ; 1978)$ cita veados, coelhos, lebres, vários pequenos roedores, ursos e porcos-espinhos como causadores de danos nos Estados Unidos. Os danos variam desde o consumo de sementes de árvores, impedindo a regeneração, até o consumo da ponteira de plântulas e retirada da casca em raízes, troncos e galhos, reduzindo o crescimento, deformando ou enfraquecendo as árvores e tomando-as suscetíveis a doenças ou a ataques de insetos. 
$\mathrm{Na}$ índia, uma variedade de herbívoros, incluindo elefantes, bisões e veados, retira a casca de árvores e lambe o câmbio (BROWNE, 1968). Roedores também causam extensivos danos na África do Sul (McNALLY, 1955). Esquilos cinza introduzidos na Grã-Bretanha causaram danos à casca de árvores, além de provocarem a extinção local de esquilos vermelhos nativos (MAITLAND, 1995). No Paquistão, o porco-espinho é considerado uma praga em florestas irrigadas (GREAVES; KHAN, 1978).

No Brasil, danos causados por roedores em povoamentos é fato comprovado há algum tempo, porém nenhum estudo efetivo sobre esses danos, efeitos e controle foi realizado. As informações disponibilizadas por várias empresas florestais do sul do Brasil indicam que esses danos vêm se tomando cada vez mais preocupantes pela intensidade e abrangência.

Schönherr et al. (1973) citam roedores como causadores de muitos problemas aos reflorestamentos, desde plantios jovens até os adultos, roendo a casca na base do tronco de coníferas exóticas nos estados do sul do Brasil. Pacas, ouriços e outros roedores causam danos em plantações de pinus no estado de São Paulo (CARVALHO; BUENO, 1975).

Neste trabalho, objetivou-se obter informações que permitam a recomendação de procedimentos que resultem numa redução do nível de ataque, a fim de diminuir os prejuízos causados por roedores em povoamentos de pinus. Tal estudo é justificado pelo nível de ataque de roedores que, em muitos povoamentos das áreas de estudos, representa danos em até 100\% das árvores.

\section{MATERIAL E MÉTODOS}

\section{Área de estudo}

O trabalho de campo foi desenvolvido em duas áreas florestais com plantios de Pinus sp na região do planalto do estado de Santa Catarina.

A fazenda Rio das Pedras, que pertence à empresa Seiva S.A. Florestas e Indústrias, está situada no município de Ponte Alta do Norte. Utilizou-se uma área denominada de "reforma", por já ter sofrido plantio e exploração com as mesmas espécies de pinus. Essa área, com 2.139 ha de efetivo plantio de $P$. taeda e P. elliottii implantados entre 1993-1995, sofreu intenso dano de roedores às árvores entre o final de 1997 e início de 2000.

A segunda área é uma propriedade privada pertencente ao Sr. Paulo Waltrick, situada no município de Bom Retiro. Constitui-se numa área de 50 ha de plantio de P. taeda, implantados no início de 1998, e apresenta danos recentes que começaram a aparecer em meados de 2000.

\section{Técnicas de redução de danos}

Devido à grande intensidade de danos causados por roedores no sítio do Sr. Paulo Waltrick, testaram-se técnicas de redução dos estragos em áreas selecionadas que apresentassem a mesma intensidade de ataque, com danos recentes e com sub-bosque semelhante, formado principalmente por capim-papuã.

Nessas áreas, foram delimitadas aleatoriamente 12 unidades amostrais de $3.600 \mathrm{~m}^{2}(60 \times 60 \mathrm{~m})$, onde, além de unidades-testemunha, foram aplicados os tratamentos de roçada, coroamento e aplicação de cabelo humano, em 3 repetições cada, descritas a seguir.

A roçada consistiu na limpeza do plantio, com a vegetação verde sendo cortada manualmente a uma altura de 5 a $10 \mathrm{~cm}$ do solo e deixada no local para secar e se decompor. O coroamento consistiu na capina manual e retirada da vegetação de sub-bosque num raio de $50 \mathrm{~cm}$ ao redor de cada árvore. A aplicação de cabelo humano, uma técnica utilizada por produtores de maçã contra a ação de lebres, segundo informações locais, consistiu em distribuir um punhado de cabelo humano ao redor da base das árvores.

Foram feitas verificações antes da aplicação dos tratamentos e após, em intervalos de dois meses (março, maio e julho), visando avaliar a eficiência de cada um desses tratamentos. Para tanto, foi utilizada a "comparação de médias nos ensaios inteiramente casualizados", baseada em Pimentel-Gomes (2000).

A verificação foi feita em sub-unidades de $400 \mathrm{~m}^{2}(20 \times 20 \mathrm{~m})$ no centro de cada uma das 12 unidades amostrais de $3.600 \mathrm{~m}^{2}$, totalizando 56 árvores por unidade, sendo anotadas as informações de cada árvore em quatro classes: árvore sem dano, com dano cicatrizado, com dano recente e árvore morta. Para a avaliação da efetividade das diferentes técnicas, levou-se em consideração o número de árvores com danos recentes identificadas em cada coleta de dados. 
Outros três procedimentos, sem rigidez estatística, também foram testados por técnicos da empresa em talhões da fazenda Rio das Pedras quanto à eficácia na redução do nível de danos.

Óleo queimado foi aplicado na base das árvores, desde o nível do solo até uma altura de $80 \mathrm{~cm}$, com brocha ou pulverizador, em toda a circunferência da árvore. Esse suposto repelente foi aplicado em todas as árvores do talhão 91 e misturado com creolina nas do talhão 85 .

Foram distribuídas 25 silhuetas de uma ave de rapina com o objetivo de, imitando inimigos naturais pela forma e movimento, afugentar os roedores. Essas silhuetas, confeccionadas em chapas de alumínio, com $60 \mathrm{~cm}$ de altura e $100 \mathrm{~cm}$ de envergadura, foram pintadas de preto e branco em faixas alternadas. Elas foram penduradas por fio de nylon fixado nas asas e em galhos de árvores de pinus, a aproximadamente $2 \mathrm{~m}$ do solo e distanciadas por $15 \mathrm{~m}$. Para esse teste, escolheu-se uma área do talhão 91 que apresentava elevado nível de dano e denso sub-bosque de gramíneas (principalmente capim-papuã). As silhuetas foram colocadas nas árvores das primeiras linhas de um talhão limítrofe a uma área de preservação.

A última técnica testada consistiu na liberação de gado em talhões de pinus, visando diminuir a vegetação de sub-bosque pelo pastoreio e pisoteio. Um grupo de 110 animais, cerca de 0,3 cabeças/ha, foi liberado em uma área de 375 ha do projeto Fazenda Rio das Pedras III.

\section{RESULTADOS E DISCUSSÃO}

\section{Histórico dos danos}

$\mathrm{Na}$ fazenda Rio das Pedras há relatos de danos causados por roedores já desde o início dos plantios da década de 60 e início dos anos 70. Como tais vestígios eram raros, não suscitaram maiores preocupações quanto a possíveis perdas nos plantios, uma vez que era um fenômeno ocasional.

Já em 1996, o problema começou a assumir proporções maiores, pela grande quantidade de árvores secas, de aproximadamente 3 anos, nos talhões. Uma verificação das árvores mortas revelou que, escondida pela vegetação herbácea do sub-bosque, a casca na base das árvores tinha sido completamente retirada. $\mathrm{O}$ ataque de roedores chegou a atingir, em determinadas áreas, $100 \%$ das árvores. Inventários expeditos revelaram que tanto árvores de $P$. taeda como de $P$. elliottii são atacadas com a mesma intensidade, que árvores muito oprimidas e de baixo crescimento são as que apresentam menor porcentagem de danos e que estes ocorrem em maior intensidade durante os meses de inverno.

No sítio do Sr. Paulo Waltrick, o povoamento foi implantado em 1998 em áreas que anteriormente eram de pastagem. A partir do final do ano de 2000, a ocorrência de árvores mortas começou a ser notada. A observação das árvores revelou danos na base das árvores cobertas por denso sub-bosque, e tais danos chegavam a atingir até $100 \%$ das árvores em certos locais.

\section{Espécie causadora dos danos}

O procedimento para a determinação da espécie de roedor causadora dos danos está disponível em Andreiv (2002). Seis espécies de roedores foram capturadas desde o início de 1999 até outubro de 2001, totalizando 91 indivíduos. Considerando a morfologia de pelos encontrados na base das árvores danificadas, a dimensão (largura) dos incisivos em painéis recentes e a forma e dimensão dos detritos produzidos em confinamento, chegou-se à conclusão de que o roedor comumente denominado de rato-deespinho, da espécie Euryzygomatomys spinosus, era o causador dos danos. Outros detalhes estão disponíveis em Andreiv (2002).

\section{Caracterização dos danos}

Os danos, na base das árvores e em todas as áreas estudadas, são semelhantes em aparência e consistem na retirada, através da roedura, da casca, que fica depositada em pedaços (média de 1,6 por 3,9 $\mathrm{cm}$ ) no solo abaixo da área danificada. Os danos podem ser superficiais, pequenas áreas onde o ritidoma $\mathrm{e}$ parte do floema são atingidos, ou mais profundos, quando, além desses, o câmbio e porções do alburno são retirados. Em danos recentes (de até 2 dias) e profundos que expõem tecido vivo, podem-se notar nitidamente sulcos verticais impressos, resultado da ação de dentes incisivos superiores, típico de roedores, sobre o alburno.

Dias após o dano, as gotas de resina que recobrem toda a área afetada começam a secar, formando uma camada de coloração branca. A reação da árvore é, inicialmente, isolar a área atacada por 
exsudação abundante de resina e, posteriormente, recobrir o tronco mediante um crescimento exagerado da casca e do xilema (FERREIRA, 1989).

Com o crescimento da árvore e para recobrir o ferimento, é formado um tecido de cicatrização. Segundo Burger e Richter (1991), o tecido de cicatrização é representado por um desvio das camadas de crescimento que, dependendo do tamanho do ferimento, podem envolvê-lo completamente.

A medição dos ferimentos, por ocasião dos inventários, revelou danos de até $26 \mathrm{~cm}$ de altura, a partir da base da árvore, e média de $13,5 \mathrm{~cm}$ de altura.

A circunferência do colo das árvores também foi afetada em variáveis proporções até um anelamento total. Entre 415 árvores danificadas e medidas, 197 (47,5\%) apresentavam mais de 50\% da circunferência do colo danificada e 10,6\% apresentavam anelamento completo, o que, conseqüentemente, deve ter provocado a morte dessas árvores. Algumas árvores, apenas $2,4 \%$, emitiram raízes próximas à região danificada como uma forma de recuperação.

O processo de morte pode ser visualmente identificado pela descoloração da copa, que vai perdendo a coloração verde escura até se tomar amarelada. Além da morte, tais danos, quando parciais, provocam ferimentos, expondo os tecidos internos a pragas e doenças, que podem afetar a resistência das árvores (SULLIVAN et al., 1993; BUSSCHE; ZEE, 1985; KOEHLER; FIRKOWSKI, 1996).

\section{Técnicas de redução de danos}

Nas parcelas submetidas à roçada, ocorreu uma significativa redução no número de árvores danificadas. Nesse tratamento, a porcentagem de árvores com danos recentes passou de $24,4 \%$ para $1,2 \%$ na primeira avaliação e para $0,6 \%$ na segunda avaliação (Tabela 1). A roçada foi, entre as técnicas testadas, a única eficiente na redução dos danos.

Tabela 1. Número (n) e porcentagem (\%) de árvores com danos recentes por tratamento avaliados dois e quatro meses após instalação.

Table 1. Number (n) and percentage (\%) of trees with recent damage in each treatment evaluated two and four months after trial installation.

\begin{tabular}{lcccccc}
\hline \multirow{2}{*}{ Tratamento } & \multicolumn{2}{c}{ Março } & \multicolumn{2}{c}{ Maio } & \multicolumn{2}{c}{ Julho } \\
\cline { 2 - 7 } & $\mathbf{n}$ & $\mathbf{\%}$ & $\mathbf{n}$ & $\mathbf{\%}$ & $\mathbf{n}$ & $\mathbf{\%}$ \\
\hline Roçada & 3,7 & 24,4 & $0,7^{*}$ & 1,2 & 0,3 & 0,6 \\
Coroamento & 13 & 23,2 & 15,3 & 27,4 & 11,7 & 20,8 \\
Cabelo humano & 14,7 & 26,2 & 13,3 & 23,81 & 10 & 17,9 \\
Testemunha & 14,3 & 25,6 & 13,7 & 24,4 & 10,3 & 18,5 \\
\hline
\end{tabular}

*Médias com diferença superior à diferença mínima significativa $(\Delta \mathrm{ij}=7,77)$.

A remoção ou destruição da cobertura vegetal é o mais adequado método para prevenir danos por ratos (THOMPSON, 1953, citado por McNALLY, 1955). Todos os animais são dependentes de água, abrigo e alimento. Assim, a eliminação de um desses recursos terá efeito direto sobre a espécie, reduzindo ou eliminando a população. Esse é um procedimento que usualmente tem efeitos mais permanentes na redução de problemas causados por animais silvestres (HAWTHORNE, 1980; FIRKOWSKI, 1993; CAUGHLEY; S1NCLAIR, 1994). A existência de vegetação herbácea freqüentemente melhora o ambiente para roedores. A utilização de herbicidas promove a redução da vegetação herbácea ou arbustiva, diminuindo a capacidade de carga do ambiente, com conseqüente decréscimo da população de roedores (TAIPNER et al., 1983). Segundo Hawthorne (1980), pomares infestados por gramíneas ou ervas daninhas são freqüentemente invadidos por roedores, e apenas a prática continuada de limpeza poderá livrar a área dos animais.

A retirada da vegetação por coroamento não diminuiu o nível de ataque. A exposição da base das árvores não foi suficiente para inibir a ação dos roedores. Cabelo humano distribuído ao redor das árvores também não tem efeito de inibir, e as parcelas com esse tratamento apresentaram nível elevado e constante de danos.

\section{Outras técnicas observadas}

Dias após a aplicação de óleo queimado puro e misturado com creolina, as árvores continuaram a ser atacadas com a mesma intensidade que antes do tratamento, demonstrando não terem eficiência como 
repelentes de roedores neste caso. Essa técnica, além de não apresentar eficiência quanto a seu objetivo, apresenta uma baixa aplicabilidade no setor florestal pela quantidade de produto requerido e alto custo de mão-de-obra para a aplicação. Assim, mesmo na utilização de um produto eficiente, esses obstáculos tomam a técnica pouco aplicável. National Academy of Sciences (1975) alega que repelentes oferecem alguma proteção durante o plantio e o início do crescimento, mas eles têm de ser aplicados repetidamente para proteção completa. Hawthorne (1980) e Anthony (1982) relatam que repelentes químicos são usados para aliviar os danos, mas seu curto tempo de persistência limita sua efetividade, além de poderem ser lavados pela chuva. Raramente os repelentes são economicamente viáveis para a aplicação em grandes áreas (NATIONAL ACADEMY OF SCIENCES, 1978). Greaves e Khan (1978) concordam que repelentes são pouco efetivos, por agirem por um curto período de tempo e por serem caros.

O uso de silhuetas de aves de rapina também não foi uma técnica eficiente na redução do nível de ataque, pois até as árvores onde as silhuetas estavam penduradas foram danificadas. A presença de um sub-bosque denso pode ter impedido a visualização das silhuetas pelos roedores e, assim, contribuído para a continuidade dos danos. Silhuetas mais elaboradas podem incluir alarmes ou emitir ultra-sons, mas exigem constante manutenção (CAUGHLEY; SINCLAIR, 1994). Mesmo se bem sucedido, esse método é limitado, por ser impraticável em grande escala (BUSSCHE; ZEE, 1995).

Dentre as técnicas alternativas testadas, a redução do sub-bosque pelo pastoreio e pisoteio por gado foi a que apresentou os melhores resultados. O gado liberado no plantio, numa proporção de 0,3 cabeça/ha, proporcionou uma grande redução do nível de ataque, muito semelhante à redução observada no tratamento roçada.

O gado pode ser liberado no plantio quando as árvores já tenham alcançado um certo tamanho para suportar a ação dos animais, como encostar-se e esfregar-se. Nesse caso foi em torno dos 3 anos de idade, quando as árvores haviam atingido $4 \mathrm{~m}$ de altura em média.

A proporção número de cabeças/ha dependerá diretamente da disponibilidade de alimento obtido do sub-bosque, sendo, assim, necessária uma avaliação da proporção adequada para cada caso. Em Imbituva (PR), constatou-se que em uma associação de pinus, pastagem nativa e gado de corte, nenhuma árvore foi danificada pelos animais e o desenvolvimento das árvores não foi afetado. Essa associação mostrou-se econômica e tecnicamente viável, pois, além de reduzir a quantidade de material combustível, diminuindo o risco de incêndios, propiciou uma produção de carne na ordem de 30 a $40 \mathrm{~kg} / \mathrm{ha} / \mathrm{ano}$ (MEDRADO, 2000).

\section{CONCLUSÃO}

Os ratos-de-espinho (Euryzygomatomys spinosus) podem ser considerados como potenciais causadores de danos em povoamentos florestais, sendo o monitoramento importante na identificação de eventuais ataques sobre os plantios, acompanhado da aplicação de efetivas técnicas de redução de danos para a manutenção da vitalidade e produtividade desses povoamentos.

Fica evidente, nesse estudo, a estreita relação entre a presença de sub-bosque e a presença de danos, visto ser o abrigo proporcionado pela vegetação uma das bases do tripé das necessidades para a existência de um animal. As técnicas que modifiquem o ambiente, através da eliminação do sub-bosque, como a roçada ou a utilização de gado, são as mais efetivas na redução de danos.

\section{AGRADECIMENTOS}

Agradecemos à CAPES pela bolsa de mestrado concedida, à Seiva S. A. Florestas e Indústrias, pelo apoio financeiro, e ao Sr. Paulo Waltrick por disponibilizar área de estudo.

\section{REFERÊNCIAS}

ANTHONY, R.M. Protecting ponderosa pine from mule deer with plastic tubes. Tree Planters Notes, Washington, DC, v. 33, n. 3, p. 22-26, 1982.

BROWNE, F.G. Pests and diseases of forest plantation trees. London: Claredon , 1330p. 1968. 
BURGER, L.M.; RICHTER, H. G. Anatomia da madeira. São Paulo: Nobel, 154p. 1991.

BUSSCHE, G.H.; ZEE, D. Damage by samanko monkeys, Cercophitecus (mitis) albogularis, to pine trees in the Northern Transvaal. South African Forestry Journal, Pretoria, n. 133, p. 43-48., 1995.

CARVAlHO, C.T.; BUENO, R.A. Animais causando danos em plantios (Mammalia, Rodentia). Silvicultura em São Paulo, n. 9, p. 39-46, 1975.

CAUGHLEY, G.; SINCLAIR, A.R.E. Wildlife ecology and management. Massachusetts: Blackwell Science, 1994. $334 \mathrm{p}$.

FERREIRA, F. A. Patologia florestal: principais doenças florestais no Brasil. Viçosa, MG: Sociedade de Investigações Florestais, 1989. 570p.

FIRKOWSKI, C. O hábitat para fauna: manipulações em micro escala. Floresta, Curitiba, v. 21, n. 1-2, p. 27-43, 1993.

GOMES, F.P. Curso de estatística experimental. 14. ed. Piracicaba: ESALQ, 2000. 477p.

GREAVES, J. H.; KHAN, A. A. The status and control of porcupines, genus Hystrix, as forest pest. Commonwealth Forestry Review, Oxford, GB, v. 57, n. 1, p. 25-32, 1978.

HAWTHORNE, D. W. Wildlife damage and control techniques. In: SCHEMNITZ, S. D. (Ed.). Wildlife management techniques manual. Washington, DC: The Wildlife Society, 1980. 686p.

KOEHLER, A.; FIRKOWSKI, C. Descascamento de pinus por macaco-prego (Cebus apella). Floresta, Curitiba, v. 24, n. 1-2, p. 61-75, 1996.

MCNALLY, J. Damage to Victorian exotic Pine plantations by native animals. Australian Forestry, Queen Victoria, v.19, n. 2, p. 87-99, 1955.

MAITLAND, M. C. Squirrel strategy. Arboricultural Journal, Dorchester on Thames, v. 19, n. 4, p. 349-356, 1995.

MEDRADO, M. J. S. Sistemas agroflorestais: aspectos básicos e indicações. In: GALVÃO P. M. (Org.). Reflorestamento de propriedades rurais para fins produtivos e ambientais: um guia para ações municipais e regionais. Colombo: Embrapa/CNPF, 2000. p.269-312.

NATIONAL ACADEMY OF SCIENCES. Pest control: an assessment of present and alternative technologies. Washington, DC: National Academy of Sciences, 1975. v.4.

NATIONAL ACADEMY OF SCIENCIES. Problemas y control de plagas de vertebrados. México: Limusa, 1978. v. 5.

SCHÖNHERR, J. Proteção Florestal: duas décadas de pesquisa em Curitiba. In: SIMPÓSIO INTERNACIONAL [SOBRE] O DESAFIO DAS FLORESTAS NEOTROPICAIS, 1991, Curitiba. O desafio das florestas neotropicais. Curitiba: [UFPR], 1991. p.188-207.

SCHÖNHERR, J.; PEDROSA-MACEDO, J.H.; HOFFMANN, D. Pragas animais nos reflorestamentos da região sul do Brasil. In: CONGRESSO FLORESTAL BRASILEIRO, 2., 1973, Curitiba. Anais...Curitiba: Federação das Indústrias do Estado do Paraná, 1973. p.161- 162.

SULLIVAN, T.P.; COATES, H.; JOZSA, L.A.; DIGOLE, P K. Influence of feeding damage by small mammals on tree growth and wood quality $\mathrm{m}$ young lodgepole pine. Canadian Journal of Forest Research, Ottawa, v.25, n.3, p. 799-809, 1993.

TAIPNER, C.L.; GARTON, E.O.; NELSON Jr., L. Pocket gophers in forest ecosystems. Fort Collins: USDA Forest Service/Intermountain Forest and Range Experiment Station, 1983. 29p. (General Technical Report, n. 154). 